\title{
ANALISIS PERBAIKAN PENJADWALAN PRODUKSI KERTAS \\ UNTUK MEMINIMUMKAN KETERLAMBATAN PRODUKSI \\ DI PABRIK PT. PUSAKA PRIMA MANDIRI \\ JL.BRIGJEN ZEIN HAMID KM 6,9 \\ DELI TUA
}

\author{
Jumadi Suratman ${ }^{1}$,Ahmad Rahim Matondang ${ }^{2}$, Nazaruddin ${ }^{3}$ \\ DepartemenTeknikIndustri, FakultasTeknik, Universitas Sumatera Utara \\ Jl. AlmamaterKampus USU, Medan 20155an \\ Email: jumadisuratman@gmail.com ${ }^{1)}$,rahimmatondang@gmail.com ${ }^{2)}$,nazaruddin@gmail.com ${ }^{3)}$
}

\begin{abstract}
Abstrak. PT. Pusaka Prima Mandiri merupakan sebuah perusahaan yang bergerak dalam bidang produksi kertas rokok dan berlokasi di jalan Zein Hamid km 6,9Deli Tua Medan Sumatera Utara. PT. Pusaka Prima Mandiri berdiri sejak tahun 2013. Dari awal berdirinya sampai saat ini berlokasi ditempat yang sama dan sudah dalam bentuk perusahaan kertas rokok. Dalam melakukan kegiatan produksi, produksi terkadang mengalami keterlambatan dalam memenuhi pesanan dari Castamer, Hal ini mungkin dapat di sebabkan karena penjadwalan produksi yang kurang tepat. Berdasarkan proses produksi. Maka penulis mengusulkan suatu penelitian pada penjadwalan yang baik. Untuk dapat meningkatkan efisiesi dalam proses produksi. Lihat Tabel 1.1 dari pengumpulan data pada Tabel 5.1 dapat dilihat dan Tabel 5.2 serta pada Tabel 5.3 dari penjadwalan produksi tahun 2013 perlu diadakan Analisis Perbaikan Penjadwalan Produksi untuk mengatasi keterlambatan ,dengan Metode CDS dan Db Hasil Perhitungan. Makespan pada Perusahaan 2.502,28 jam dengan selisih 637,28 jam atau sebesar 25,59 \%.maka pada pengolahan data dilakukan Hipotesis Ho ditolak pada data tahun 2013, ini jelas bahwa Penjadwalan harus dipebaiki. Jadi untuk tahun 2014, Ho diterima, jadi terjadi peningkatan produksi dan pencapaian target $94 \%$, dapat dilihat pada grafik gambar 10.1.Grafik Barang 1/2 jadi produksi pada tahun 2013 dan 2014 dengan target produksi sebesar $94 \%$ meminimalisir barang 1/2 jadi atau Barang masih dalam proses sebesar $6 \%$ dari ketepatan waktu sebesar $94 \%$.
\end{abstract}

Kata kunci: Penjadwalan produksi,keterlabatan produksi dan barang $1 / 2$ jadi.

Abstract. PT. Pusaka Prima Mandiri is a company engaged in the production of cigarette paper and located at $6.9 \mathrm{~km}$ road Hamid Zein Deli Tua Medan North Sumatra. PT. Pusaka Prima Mandiri was established in 2013 from its inception to date are located in the same place and are already in the form of cigarette paper company.In doing so, the production, the production sometimes experience delays in fulfilling orders from Castamer, This may be caused due to the lack of proper production scheduling.Based on the production process. The authors propose a study on good scheduling. In order to improve efisiesi in the production process. See Table 1.1 of the data collection can be seen in Table 5.1 and Table 5.2 and Table 5.3 of scheduling production in 2013 should be held Repair Analysis Production Scheduling to overcome delays, with CDS and Db Method Calculation Results. Makespan on the Company 2502.28 hours by a margin of 637.28 hours or by $25.59 \%$ It so the data processing is done hypothesis Ho is rejected on the data in 2013, it is clear that the scheduling should dipebaiki. So for 2014, Ho is accepted, so an increase in production and the achievement of the target of $94 \%$, can be seen in the graphic image so 10.1. Grafik 1/2 goods production in 2013 and 2014 with a production target of $94 \%$ to minimize $1 / 2$ finished goods or goods are still in the process $6 \%$ of punctuality of $94 \%$.

Keywords: production scheduling, delay of production, half finished goods

\footnotetext{
${ }^{1}$ Mahasiswa, Departemen Teknik Industri, Fakultas Teknik, Universitas Sumatera Utara

${ }^{2}$ Dosen Pembimbing, Departemen Teknik Industri, Fakultas Teknik, Universitas Sumatera Utara
} 


\section{PENDAHULUAN}

PT. Pusaka Prima Mandiri merupakan sebuah perusahaan yang bergerak dalam bidang produksi kertas rokok dan berlokasi di jalan Brigjen Zein Hamid km 6,9 Deli Tua Medan Sumatera Utara. PT. Pusaka Prima Mandiri berdiri sejak tahun 2013, dari awal berdirinya sampai saat ini berlokasi ditempat yang sama dan sudah dalam bentuk perusahaan kertas rokok.

Dalam melakukan kegiatan produksi, produksi terkadang mengalami keterlambatan dalam memenuhi pesanan dari Costomer. Hal ini mungkin dapat disebabkan karena penjadwalan produksi yang kurang tepat yang terlihat pada tabel 1berikut ini.

Tabel.1. Permintaan Produksi Kertas dan Realisasi Produksi serta Pencapaian Target

Produksi Ketas Rokok di PT.PPM Thn 2013

\begin{tabular}{clccc}
\hline & & PERMI & REA & PENCAP \\
No & Bulan & NTAAN & LISA & AIAN \\
& & KERTA & SI & PRODU \\
& & S & PRO & KSI (\%) \\
& & ROKOK & DUK & \\
& & DALAM & SI & \\
& & ROLL & DAL & \\
& & & AM & \\
& & & ROL & \\
& & & L & \\
\hline $\mathbf{1}$ & Januari & 460 & 416 & 90,4 \\
$\mathbf{3}$ & Pebruari & 378 & 370 & 97,9 \\
$\mathbf{4}$ & Maret & 420 & 390 & 92,8 \\
$\mathbf{5}$ & April & 227 & 198 & 87,2 \\
$\mathbf{6}$ & Juni & 460 & 420 & 91,3 \\
$\mathbf{7}$ & Juli & 378 & 370 & 97,9 \\
$\mathbf{8}$ & Agustus & 420 & 410 & 97,6 \\
$\mathbf{9}$ & September & 375 & 220 & 96,9 \\
$\mathbf{1 0}$ & Oktober & 460 & 420 & 98,6 \\
$\mathbf{1 1}$ & Nopember & 420 & 416 & 97,8 \\
$\mathbf{1 2}$ & Desember & 411 & 405 & 98,5 \\
\hline & & & &
\end{tabular}

Berdasarkan Tabel 1. Pencapaian jumlah Permintaan produksi belum memenuhi target atau belum $100 \%$ Sehingga perludilakukan penelitian untuk memperbaiki Jadwal Produksi. Karena adanya Gap antara Permintaan dengan realisasi nya. Permintaan Produksi pada bulan januari 2013 adalah 460 roll dibagi dengan realisasi 416 roll dengan hasil 90,4 \% dan pada bulan April adalah 87 $\%$ terjadi penurunan hasil produksi ada Gap yang lebih besar lagi. Jadi perbaikan penjadwalan produksi dikarenakan adanya barang $1 / 2$ jadi di lantai pabrik yang masih tertinggal banyaknya permintaan - realisasi $=460$ roll -416 roll $=44$ roll . Pada phenomena ini terjadi masalah keterlambatan produksi pada perusahaan PT. Pusaka Prima Mandiri sebagai produksen kertas rokok antara lain
1. Belum melakukan penjadwalan secara optimal. Akibatnya terjadi keterlambatan produksi kertas rokok pada pelanggan dan pemesanan kertas untuk PT. Bentul Group di Malang dan PT. Nojorono di kudus serta PT. Sampoena di Surabaya.

2. Jadwal produksi sering tidak terpenuhi adanya barang $1 / 2$ jadi dilantai pabrik pesanan selalu terlambat. Untuk pelanggan atau konsumen dari PT. Pusaka Prima Mandiri. Sehingga perlu perbaikan penjadwalan produksi di pabrik PT. Pusaka Prima Mandiri.

\section{METODE PENELITIAN}

Metode Penelitian diawali dengan pengamatan langsung di perusahaan serta melakukan wawancara dengan pihak perusahaan untuk mengetahui masalah-masalah yang ada. Kemudian di lakukan pengambilan data baik primer maupun secunder. Data primer berupa waktu pengamatan tiap operasi yang diproleh dari pengukuran langsung pada perusahaan untuk melihat secara langsung kondisi lantai produksi secara rill. Sedangkan data sekunder di proleh dari data masalah perusahaan catatan perusahaan. Data yang di kumpulkan antara lain jam kerja, urutan proses produksi, waktu set up mesin, waktu yang di butuhkan untuk menyelesaikan satu job, dan data pesanan dari konsumen. Data yang di dapat kemudian di olah untuk di buat penjawalan yang tepat bagi perusahaan. Kemudian di Analisis. Apakah penjadwalan yang di buat sudah dapat mengatasi permasalahan perusahaan atau belum. Karena itu perlu di lakukan perbandingan antara hasil penjadwalan awal dengan hasil penjadwalan usulan. Penelitian ini di laksanakan di Pabrik kertas rokok PT. Pusaka Prima Mandiri daerah Deli Tua pada bulan April 2014 s/d Desember 2014. Data yang di ambil pada penelitian ini adalah data permintaan produksi dan realisasi produksi serta waktu proses keterlambatan produksi dari periode januaru 2013 s/d Desember 2013 dan periode januari 2014 s/d Desember 2014. Objek penelitian Analisis perbaikan penjadwalan produksi kertas rokok di PT. Pusaka Prima Mandiri. Pengumpulan data di proleh dengan melakukan observasi / pengamatan langsung di lapangan yaitu pada waktu pabrik berproduksi. Landasan teori yang digunakan dalam menganalisa dan pemecahan masalah yang ada berdasarkan metode CDS dan Db serta Statistik.pengolahan data adalah sebagai berikut:

1. Hitung waktu proses produksi, waktu set up dan waktu absen operator (kariawan pabrik).

2. Penetuan waktu rata-rata jumlah produksi dan waktu selesai produksi kertas rokok

3. Penentuan distribusi keterlambatan

4. Penentuan Metode dan Uji Statistik

5..Penentuan Perbandingan setelah perbaikan penjadwalan produksi kertas rokok. Kemudian buat 
Kerangka konseptual yang terdiri dari aliran proses berpikir sistematis yang di awali dari latar belakang penelian perumusan masalah, Analisis permasalahan serta saran / solusi. Alternatif terhadap masalah tersebut berdasarkan logika hubungan sebab akibat pola sederhana pada hubungan jalur aliran dan aktivitas.

Contoh :

Pengaruh keterlambatan produksi sampai ke konsumen atau pelanggan terlihat pada Gambar 1.

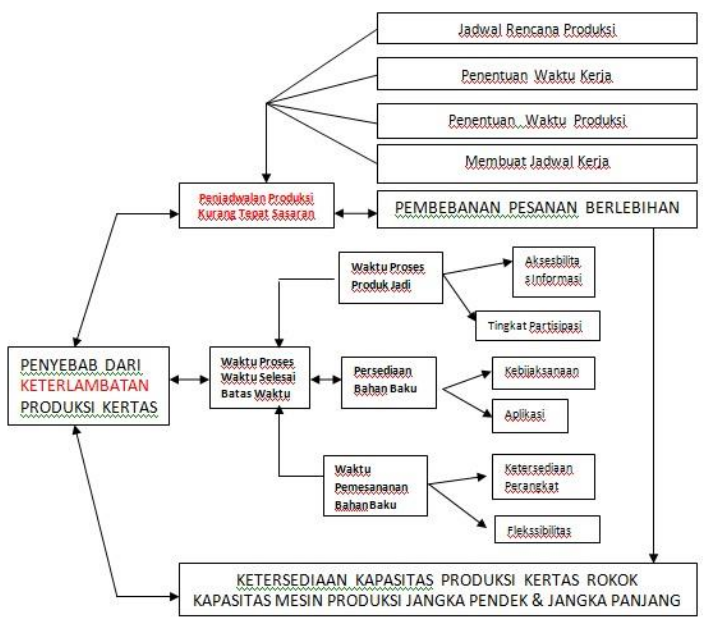

Gambar 1. Kerangka komseptual penjadwalan produksi

Keterangan : Identifikasi dan Analisa teori yang di aplikasikan

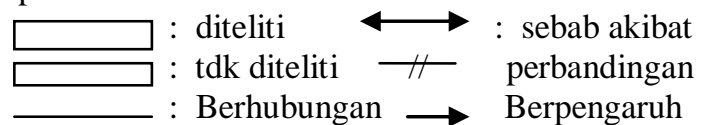

6. Identifikasi Objek Penelitian, objek yang diteliti adalah keterlambatan yang timbul pada penjadwalan produksi kurang tepat sasaran yang dituju oleh perusahaan, karena proses pengaturan pada proses produksi kertas rokok yang dialami pada tahun 2013.

7.MetodePengumpulan Data Dalam mengumpulkan data terdapat dua hal yang perlu diperhatikan yaitu:

a. Data Primer

Data primer adalah data yang diukur pada saat penelitian lapangan oleh peneliti pada objek, dimana data diproleh secara langsung diperusahaan PT. Pusaka Prima Mandiri yang sedang diteliti, Dengan observasi melalui teknik observasi ini penulis mengumpulkandata dengan melakukan pengamatan langsung diperusahaan terhadap masing-masing operator pada setiap stasiun kerja.

b. Data Sekunder

Data sekunder adalah data diproleh peneliti dengan melakukan pengumpulan data yang telah ada diperusahaan (dokumen Perusahaan).
Data yang dikumpulkan selama melakukan penelitian di PT. Pusaka Prima Mandiri adalah:

1. Data gambaran umum perusahaan menyangkut sejarah perusahaan, lokosi perusahaan, sarana dan prasarana perusahaan, pemasaran dan jumlah produksi.

2. Data tentang proses produksi di pabrik PT. Pusaka Prima Mandiri.

3. Penjadwalan Produksi tahun 20013 dan tahun 2014 ada terlampir dilampiran.

4. Data tentang organisasi dan manjemen meliputi struktur organisasi perusahaan dan hubungan kerja, tugas dan tanggung jawab, jumlah tenaga kerja dan jam kerja perusahaan, sistem pengupahan dalam perusahaan.

5. Untuk menyusun distribusi frekuensi data kita membutuhkan jumlah kelas dengan menggunakan rumus : $\mathrm{k}=1+3,3 \log \mathrm{n}$ dan $\mathrm{i}=$ jarak $/ 1+3,3 \log \mathrm{n}$ dan rata - rata hitung $\mathrm{x}=\mathrm{x}_{1}$ $+\mathrm{x}_{2} \ldots \mathrm{x}_{\mathrm{n}} / \mathrm{n}$.

6. Penyelesaian:

$\mathrm{H}_{\mathrm{o}}=$ Hasil produksi telah sesuai dengan target produksi yang telah ditetapkan sebelumnya.

$\mathrm{H}_{1}=$ Hasil produksi tidak sesuai dengan target produksi yang di tetapkan sebelumnya.

$\alpha=0,05$. Banyaknya katagori adalah $\mathrm{n}$ ( bulan ) dan tingkat kesalahan adalah 0,05 atau 0,01 maka nilai distribusi Chi - kuadrat:

$\mathrm{X}_{\alpha, \mathrm{k}-1}^{2}=\mathrm{X}_{0,05,12-1}^{2}$ atau $\mathrm{X}^{2}$ hitung $\leq \mathrm{X}_{\text {tabel }}^{2}$ maka diterima.

Uji hipotesis bagi eksperimen atau penelitian dengan dau atau lebih katagoriUji ini dinamakan uji kecocokan ( good ness - of - fit bests )Uji hipotesis tentang table konfingen yang terdiri uji independensi Sebagai contoh, kepuasan pelanggan atau konsumen biasa di bagi menjadi 4 katagori:

$\mathrm{A}=$ Sangat puas $=$ tepat waktu dari pesanannya $(100 \%)$.

$\mathrm{B}=$ Puas $=$ keterlambatan masih bisa ditanggulangi dari persediaan $\quad(95-85 \%)$

$\mathrm{C}=$ Kurang puas $\quad=$ keterlabatan ampir tidak dapat ditanggulagi. $(80-65 \%)$

$\mathrm{D}=$ tidak puas $\quad=$ tidak dapat ditanggulangi. $(64-50 \%)$

8. Metode Pengolahan Data,Indentfikasi dan Definisi Variabel. Dapat diidentifikasi variabel variabel yang berhubungan dengan permasalahan, yaitu sebagai berikut:

1. Waktu Proses

Waktu Proses adalah waktu yang diperlukan untuk pengerjaan tiap operasi dalam tiap job, termasuk didalamnya waktu set up dan waktu persiapan.

2. Wakyu Baku

Waktu baku adalah waktu yang dibutuhkan pekerja secara normal waktu baku ini diproleh melalui pengukuran waktu kerja dengan jam henti (Stop wath)

3. Data Permintaan 
Data permintaan adalah jumlah pesanan atau permintaan dari konsumen pada masing masing tipe job. Data permintaan ini merupakan data sekunder yang diproleh dari perusahaan untuk permintaan tiap job pengerjaan, data ini di perlukan untuk menghitung total pengerjaan waktu untuk masing-masing job.

4. Data waktu mengerjakan job.

Data waktu ini merupakan pengolahan dari data waktu baku dan data permintaan.

5. Analisa Data

Untuk menjadwalkan $\mathrm{N}$ job $\mathrm{M}$ digunakan beberapa metode penjadwalan antara lain adalah:

a. Metode Campbell Dudeck and Smith ( CDS )

b. Metode Dannenbring ( Db )

6. Perbandingan data tahun 2013 dengan tahun 2014

\section{HASIL DAN PEMBAHASAN}

3.1. Pengujian Keseragaman Data Waktu Produksi Kertas Rokok

Keseragaman Data perlu dilakukan terlebih dahulu sebelum melakukan perhitungan waktu efektif, jumlah pengamatan waktu kegiatan proses produksi kertas rokok di PT. Pusaka Prima Mandiri, dilakukan sebanyak 81 kali padaTahun 2013 dan pada tahun 2014 sebanyak 84 kali.

\subsubsection{Langkah - langkah Dalam Pengujian Keseragaman Data}

Adapun langkah - langkah dalam pengujian keseragaman data dapat dihitung dengan cara sebagai berikut:

a. Menghitung rata-rata

$$
\overline{\mathrm{x}}=\frac{\sum \mathrm{xi}}{\sum \mathrm{n}}
$$

Dimana $\mathrm{x}_{\mathrm{i}}=$ Besarnya waktu penyelesaian yang teramati selama pengukuran pendahuluan dilakukan. $\mathrm{n}$ = Banyaknya pengukuran yang dilakukan.

b. Menghitung standar deviasi sebenarnya dari waktu penyelesaian

$\sigma=\sqrt{\frac{\sum(\mathrm{x}-\mathrm{x})}{\mathrm{N}-1}}$

\footnotetext{
Dimana $\mathrm{N}=$ Jumlah pengamatan pendahuluan yang telah dilakukan

$\mathrm{X}=$ waktu rata - rata

$\sigma \quad=$ Standar Deviasi
}

\subsubsection{Menghitung Jumlah Pengukuran Yang Sebenarnya}

Untuk menentukan jumlah pengukuran waktu kerja yang sebenarnya

Diperlukan dengan tingkat ketelitian $5 \%$ dan tingkat keyakinan $95 \%$ maka

Dipergunakan rumus:

$\mathrm{N}=\sqrt{\frac{\mathrm{n} \sum \mathrm{x} 2-\left(\sum \mathrm{xi}\right) 2}{\left(\sum \mathrm{xi}\right)}}$.

Dimana:

$\mathrm{N}$ = Jumlah pengukuran yang sebesarnya diperlukan

$\mathrm{n}$ = Jumlah data setelah dilakukan uji keseragaman data

\subsubsection{Memperpendek Waktu Penyiapan}

Untuk memperpendek waktu penyiapan perlu dilakukan dua fase penyiapan, yaitu:

1. Fase penyiapan Eksternal

Seperti penyiapan terlebih dahulu tenaga kerja, peralatan dan mesin berikutnya dan bahan yang diperlukan, serta memindahkan peralatan dan bahan baku serta bahan penolong dll.

2. Fase penyiapan Internal

Fase dimana pekerja harus memusatkan perhatian pada pergantian peralatan dan bahan sesuai dengan perincian yang terdapat dalam pesanan berikutbya, sementara mesin bekerja dan berhenti.

\subsubsection{Tata Letak Proses Produksi}

1. Menurut JIT tata letak proses dan mesin akan disusun untuk melancarkan aliran produksi. Seorang pekerja menangani beberapa mesin dari berbagai Waktu proses produksi kertas rokok $=166,6666 \mathrm{jam}$

2. Waktu absen operator $5 \%$ sampai $10 \%$ $=16,6666$ jam

3. Waktu Set up Mesin $=32,8662$ jam

4. Waktu selesai produksi /Makespan Perusahaan rill $=216$ jam

5. Jumlah produksi kertas rokok $=460$ roll

proses. Tiap proses harus dikendalikan secara otomatis. Pengendalian ini menjamin bahwa produksi tidak berlangsung dalam kecepatan produksi kurang dari kebutuhan harus di kendalikan dalam keadaan norma. ${ }^{2}$ ) sesuai dengan permintaan.

\subsection{Menghitung waktu kerja}

Menghitung waktu kerja yang tersedia dalam kurun perencanaan tertentu untuk menghitung waktu kerja yang tersedia diketahui 
untuk satu tahun tersedia 250 hari kerja dan satu hari kerja pabrik bekerja 8 jam, maka waktu kerja yang tersedia adalah $250 \times 8$ jam $=2000$ jam Jadi rata-rata 1 bulan kerja $=2000$ dibagi 12 bulan $=$ 166,6666 jam, Makespan Perusahaan riil adalah:

1. Waktu proses produksi kertas rokok= 166,6666 jam

2. Waktu absen operator $5 \%$ sampai $10 \%=$ 16,6666 jam

3. Waktu Set up Mesin = 32,8662 jam

4. Waktu selesai produksi /Makespan Perusahaan rill $=216$ jam

5. Jumlah produksi kertas rokok $=460$ roll

Tabel 2. Makespan Perusahaan, Waktu

Proses, Waktu absenWaktu set up Waktu

Selesai dan Jumlah hasil Produksi kertas rokok thn 2013

\begin{tabular}{|c|c|c|c|c|c|}
\hline No & $\begin{array}{c}\text { Jumlah } \\
\text { Produk } \\
\text { ( Roll ) }\end{array}$ & $\begin{array}{l}\text { Waktu } \\
\text { Proses } \\
\text { ( Jam ) }\end{array}$ & $\begin{array}{l}\text { Waktu } \\
\text { Absen } \\
\text { ( Jam ) }\end{array}$ & $\begin{array}{l}\text { Waktu } \\
\text { Set up } \\
\text { ( Jam) }\end{array}$ & $\begin{array}{c}\text { Wakt } \\
\text { u } \\
\text { selesa } \\
\text { i } \\
\text { ( Jam } \\
\text { ) }\end{array}$ \\
\hline 1 & 460 & $\begin{array}{c}166,666 \\
6\end{array}$ & 16,6666 & 32,8668 & $\begin{array}{c}216,2 \\
0\end{array}$ \\
\hline 2 & 378 & $\begin{array}{c}145,579 \\
3\end{array}$ & 14,5579 & 17,0228 & $\begin{array}{c}177,1 \\
6\end{array}$ \\
\hline 3 & 420 & $\begin{array}{c}152,223 \\
9\end{array}$ & 15,2224 & 29,9537 & $\begin{array}{c}197,4 \\
0\end{array}$ \\
\hline 4 & 227 & 52,6408 & 5,2641 & 48,7851 & $\begin{array}{c}106,6 \\
9\end{array}$ \\
\hline 5 & 460 & $\begin{array}{c}166,666 \\
6\end{array}$ & 16,6666 & 32,8668 & $\begin{array}{c}216,2 \\
0\end{array}$ \\
\hline 6 & 378 & $\begin{array}{c}145,990 \\
1\end{array}$ & 14,5990 & 17,0709 & $\begin{array}{c}177,6 \\
6\end{array}$ \\
\hline 7 & 420 & $\begin{array}{c}152,223 \\
9\end{array}$ & 15,2224 & 29,9537 & $\begin{array}{c}197,4 \\
0\end{array}$ \\
\hline 8 & 227 & 52,6408 & 5,2641 & 48,8955 & $\begin{array}{c}206,8 \\
0\end{array}$ \\
\hline 9 & 375 & $\begin{array}{c}143,869 \\
5\end{array}$ & 14,3869 & 18,2236 & $\begin{array}{c}176,4 \\
8\end{array}$ \\
\hline 10 & 460 & $\begin{array}{c}166,666 \\
6\end{array}$ & 16,6666 & 32,8668 & $\begin{array}{c}216,2 \\
0\end{array}$ \\
\hline 11 & 320 & $\begin{array}{c}137,321 \\
7\end{array}$ & 13,7321 & 46,3462 & $\begin{array}{c}197,4 \\
0\end{array}$ \\
\hline 12 & 411 & $\begin{array}{c}148,912 \\
9\end{array}$ & 14,8912 & 29,3659 & $\begin{array}{c}193,1 \\
7\end{array}$ \\
\hline
\end{tabular}

Tabel 3. Makespan Perusahaan ,Waktu Proses,

Waktu absenWaktu set up Waktu Selesai dan

Jumlah hasil Produksi kertas rokok thn 2014

\begin{tabular}{lccccc}
\hline No & $\begin{array}{c}\text { Jumlah } \\
\text { Produk } \\
\text { ( Roll ) }\end{array}$ & $\begin{array}{c}\text { Waktu } \\
\text { Proses } \\
(\text { Jam })\end{array}$ & $\begin{array}{c}\text { Waktu } \\
\text { absen } \\
(\text { Jam })\end{array}$ & $\begin{array}{c}\text { Waktu } \\
\text { set up } \\
(\text { Jam })\end{array}$ & $\begin{array}{c}\text { Wakt } \\
\mathbf{u} \\
\text { selesai } \\
\text { ( Jam } \\
\text { ) }\end{array}$ \\
\hline $\mathbf{1}$ & 437 & 158,333 & 15,8333 & 31,2234 & 205,39 \\
$\mathbf{2}$ & 408 & $\begin{array}{c}141,666 \\
6\end{array}$ & 14,1666 & 35,9168 & 191,76 \\
$\mathbf{3}$ & 425 & 147,569 & 14,7569 & 37,4238 & 199,75 \\
& & 3 & & & \\
$\mathbf{4}$ & 440 & 152,777 & 15,2777 & 38,7446 & 206,80 \\
& & 7 & & & \\
& & & & &
\end{tabular}

$\begin{array}{llllll}5 & 456 & 158,333 & 15,8333 & 39,8535 & 214,02\end{array}$

Tabel 3. Makespan Perusahaan ,Waktu Proses, Waktu absenWaktu set up Waktu Selesai dan Jumlah hasil Produksi kertas rokok thn 2014 (Lanjutan)

\begin{tabular}{|c|c|c|c|c|c|}
\hline No & $\begin{array}{c}\text { Jumlah } \\
\text { Produk } \\
\text { ( Roll ) }\end{array}$ & $\begin{array}{l}\text { Waktu } \\
\text { Proses } \\
\text { ( Jam ) }\end{array}$ & $\begin{array}{l}\text { Waktu } \\
\text { absen } \\
\text { ( Jam ) }\end{array}$ & $\begin{array}{l}\text { Waktu } \\
\text { set up } \\
\text { ( Jam ) }\end{array}$ & $\begin{array}{c}\text { Wakt } \\
\text { u } \\
\text { selesai } \\
\text { ( Jam } \\
\text { ) }\end{array}$ \\
\hline 6 & 442 & $\begin{array}{c}153,472 \\
1\end{array}$ & 15,3472 & 38,9207 & 207,74 \\
\hline 7 & 460 & $\begin{array}{c}166,666 \\
6\end{array}$ & 16,6666 & 32,8668 & 216,20 \\
\hline 8 & 442 & $\begin{array}{c}153,472 \\
1\end{array}$ & 15,3472 & 38,9207 & 207,74 \\
\hline 9 & 452 & $\begin{array}{c}156,944 \\
3\end{array}$ & 15,6944 & 39,8013 & 212,44 \\
\hline 10 & 480 & $\begin{array}{c}166,666 \\
6\end{array}$ & 16,6666 & 42,2666 & 225,60 \\
\hline 11 & 442 & $\begin{array}{c}153,472 \\
1\end{array}$ & 15,3472 & 38,9207 & 207,74 \\
\hline 12 & 440 & $\begin{array}{c}152,777 \\
7\end{array}$ & 15,2777 & 38,7446 & 206,80 \\
\hline
\end{tabular}

\subsection{Pemecahan Masalah}

Penjadwalan adalah suatu kegiatan perancangan berupa pengalokasian sumber daya baik mesin maupun tenaga kerja untuk menjalankan sekumpulan tugas tersebut kepada bermacammacam pusat-pusat kerja untuk di proses. Permasalahan penjadwalan merupakan pengaturan waktu dari suatu kegiatan operasi. Tujuan penjadwalan untuk meminimalkan waktu proses, waktu absen, waktu set up. Ketika suatu job tidak dapat di pisah untuk permasalahan yang sederhana kita mengasumsikan tidak ada pemisahan job, maka shop loading dapat di buat dengan mudah dengan menggunakan Gantt Chart dilihat pada gambar di bawah ini sebagai berikut:

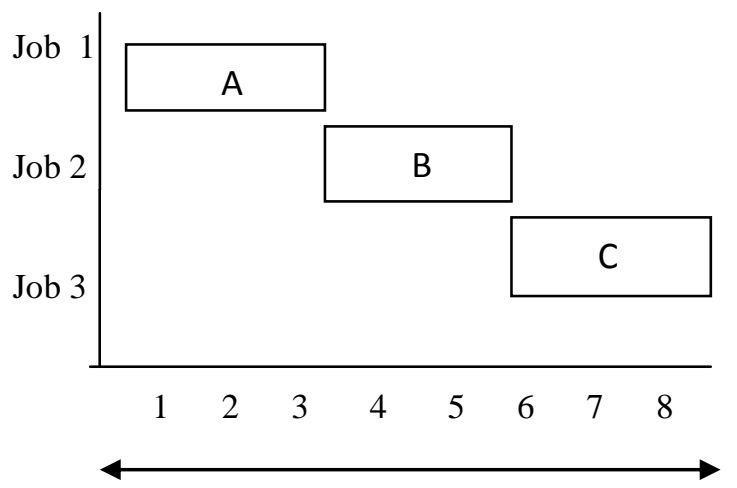

Waktu Proses Produksi

Gambar 2. Gantt Chart Penjadwalan Produksi

Makespan Penjadwalan Usulan, dari jumlah waktu perhitungan makespan Metode Campbell Dudeck \& Smith ( CDS ) dengan metode Dannenbring ( Db ) dibawah ini merupakan selisih waktu antara dua metode ini untuk mengetahui 
penggunaan metode dengan waktu yang paling efektif, dimana table menujukkan bahwa metode CDS dan Db menunjukkan waktu yang terkecil. Metode penugasan merupakan cara pembebanan pekerja-pekerja untuk job-job dapat di Tabel 4 berikut ini.

Tabel 4.Untuk Jam Kerja Produksi Kertas Rokok pada Tahun 2013

\begin{tabular}{llcc}
\hline No & $\begin{array}{l}\text { Periode } \\
\text { Bulan }\end{array}$ & $\begin{array}{c}\text { Metode } \\
\text { CDS } \\
\text { ( jam })\end{array}$ & $\begin{array}{c}\text { MetodeDb } \\
\text { ( jam ) }\end{array}$ \\
\hline 1 & Januari & 195,52 & 195,52 \\
2 & Februari & 173,90 & 173,90 \\
3 & Maret & 183,30 & 183,30 \\
4 & April & 93,06 & 93,06 \\
5 & Mei & 197,40 & 197,40 \\
6 & Juni & 173,90 & 173,90 \\
7 & Juli & 192,70 & 192,70 \\
8 & Agustus & 103,40 & 103,40 \\
9 & September & 173,90 & 173,90 \\
10 & Oktober & 197,40 & 197,40 \\
11 & Nopember & 195,52 & 195,52 \\
12 & Desember & 190,35 & 190,35 \\
\hline & Jumlah & $\mathbf{2 0 7 0 , 3 5}$ & $\mathbf{2 0 7 0 , 3 5}$ \\
\hline
\end{tabular}

Harga rata-rata jam kerja usulan CDS dan Db adalah:

$\overline{\mathrm{x}}_{1}=\frac{\sum \mathrm{xi}}{\sum \mathrm{n}}=\frac{2070,35}{12}=172,5251 \mathrm{jam}$

Makespan Riil Perusahaan PT. Pusaka Prima Mandiri. Data waktu proses keseluruhan pada perusahaan di dapat dari hasil laporan akhir penyelesaian keseluruhan job adalah 30 hari atau 28 hari. Pada bulan januari sampai bulan Desember tahun 2013 pada PT. Pusaka Prima Mandiri dapat dilihat pada Tabel 5 dibawah ini. Makespan Penjadwalan job 1,2,3, banyaknya mesin dan operator.

Tabel 5. Jam Kerja Makespan Perusahaan pada Tahun 2013

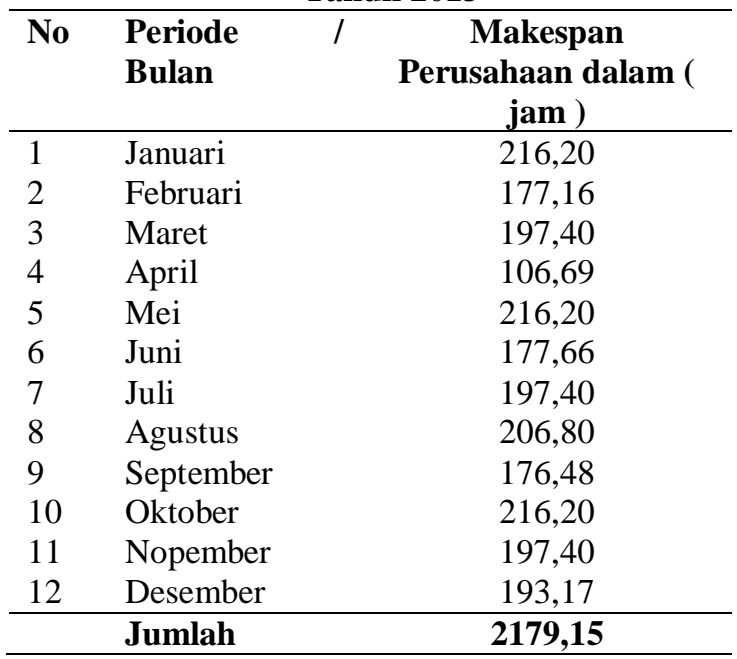

Hasil rata=rata jam kerja riil perrusahaan adalah: $\overline{\mathrm{x}}_{1}=\frac{\sum \mathrm{xi}}{\sum \mathrm{n}}=\frac{2179,15}{12}=181,5958 \mathrm{jam}$

Hasil selisih jam kerja Riil perusahaan dengan jam kerja Metode CDS dan Db rata - rata adalah: $\overline{\mathrm{x}}_{1}-\overline{\mathrm{x}}_{2}=181,5958$ jam $-172,5251$ jam $=9,0667$ jam kerja. Berikut di bawah ini merupakan selisih waktu metode usulan( Tabel 4) yang paling kecil dengan kondisi riil perusahaan ( Tabel 5 ) untuk mengetahui penggunaan dengan waktu yang paling efektif.

Tabel 6. Makespan Perusahaan dengan metode CDS \&Db serta Selisihnya

\begin{tabular}{|c|c|c|c|c|c|}
\hline No & $\begin{array}{l}\text { Periode } \\
\text { /Bulan }\end{array}$ & $\begin{array}{c}\text { Makesp } \\
\text { an } \\
\text { Perusah } \\
\text { aan } \\
\text { (jam) }\end{array}$ & $\begin{array}{c}\text { Makesp } \\
\text { an } \\
\text { Perusa } \\
\text { haan } \\
\text { (jam) }\end{array}$ & $\begin{array}{c}\text { Seli } \\
\text { sih } \\
( \\
\text { ja } \\
\text { m) }\end{array}$ & $\begin{array}{c}\text { Perse } \\
\text { ntase } \\
(\%)\end{array}$ \\
\hline 1 & Januari & 21,28 & 195,52 & $\begin{array}{l}20 \\
76\end{array}$ & 9,6 \\
\hline 2 & Februari & 177,16 & 173,90 & $\begin{array}{c}3,2 \\
6\end{array}$ & 1,6 \\
\hline 3 & Maret & 196,40 & 183,30 & $\begin{array}{l}14, \\
10\end{array}$ & 7,1 \\
\hline 4 & April & 106,69 & 93,06 & $\begin{array}{l}13, \\
63\end{array}$ & 12,77 \\
\hline 5 & Mei & 216,20 & 197,40 & $\begin{array}{l}18 \\
80\end{array}$ & 8,69 \\
\hline 6 & Juni & 177,66 & 173,90 & $\begin{array}{c}3,7 \\
6\end{array}$ & 2,11 \\
\hline 7 & Juli & 197,40 & 192,70 & $\begin{array}{c}4,7 \\
0\end{array}$ & 2,38 \\
\hline 8 & Agustus & 206,80 & 103,40 & $\begin{array}{l}103 \\
40\end{array}$ & 50 \\
\hline 9 & September & 176,48 & 173,90 & $\begin{array}{c}2,5 \\
8\end{array}$ & 1,46 \\
\hline 10 & Oktober & 216,20 & 197,40 & 18,80 & 8,69 \\
\hline 11 & November & 197,40 & 195,52 & 1,88 & 0,95 \\
\hline 12 & $\begin{array}{l}\text { Desember } \\
\text { Jumlah }\end{array}$ & $\begin{array}{l}193,17 \\
2179,15\end{array}$ & $\begin{array}{l}190,35 \\
2070,35\end{array}$ & $\begin{array}{l}2,82 \\
208,49\end{array}$ & $\begin{array}{l}1,45 \\
9,56\end{array}$ \\
\hline
\end{tabular}

Analisa Hasil perhitungan Makespan. Dari hasil yang telah di peroleh dapat di ketahui Jumlah Makespan dengan menggunakan metode CDS dan Db adalah 2070,35 jam kerja di bandingkan dengan Makespan pada perusahaan adalah 2179,15 jam kerja dengan selisih 208,49 jam kerja atau sebesar $9,56 \%$. Dimana metode yang di usulkan lebih efektif dari Makespan di perusahaan.Makespan Penjadwalan Usulan. Untuk perbaikan Penjadwalan produksi pada tahun 2014 dapat kita lihat di Tabel 7 di bawah ini.

Tabel 7. Untuk Jam Kerja Produksi Kertas Rokok pada Tahun 2014

\begin{tabular}{llcc}
\hline No & $\begin{array}{l}\text { Periode } \\
\text { Bulan }\end{array}$ & $\begin{array}{c}\text { Metode } \\
\text { CDS } \\
\text { ( Jam ) }\end{array}$ & $\begin{array}{c}\text { MetodeDb } \\
\text { ( Jam ) }\end{array}$ \\
\hline 1 & Januari & 166 & 166 \\
2 & Februari & 152 & 152 \\
3 & Maret & 161 & 161 \\
4 & April & 120 & 120 \\
5 & Mei & 167 & 167 \\
6 & Juni & 157 & 157
\end{tabular}




$\begin{array}{llll}7 & \text { Juli } & 165 & 165 \\ 8 & \text { Agustus } & 127 & 227 \\ 9 & \text { September } & 157 & 157\end{array}$


Tabel 7. Untuk Jam Kerja Produksi Kertas Rokok pada Tahun 2014 (Lanjutan)

\begin{tabular}{llcc}
\hline No & $\begin{array}{l}\text { Periode } \\
\text { Bulan }\end{array}$ & $\begin{array}{c}\text { Metode } \\
\text { CDS } \\
(\text { Jam })\end{array}$ & $\begin{array}{c}\text { MetodeDb } \\
\text { ( Jam ) }\end{array}$ \\
\hline 10 & Oktober & 167 & 167 \\
11 & Nopember & 166 & 166 \\
12 & Desember & 164 & 164 \\
\hline & Jumlah & $\mathbf{1 8 6 9}$ & $\mathbf{1 8 6 9}$ \\
\hline
\end{tabular}

Lakukan Uji hipotesisa apakah hasil produksi telah sesuai atau tidak sesuai dengan target produksi yang telah ditetapkan sebelumnya Gunakan tingkat kesalahan $5 \%$.

\subsection{Evaluasi}

Dari kasus diatas dapat disimpulkan bahwa hasil produksi telah sesuai dengan target Produksi yang telah di tetapkan sebelumnya.Evaluasi ( Pemecahan Masalah ) Data yang diproleh dari tahun 2013 sebelum perbaikan penjadwalan produksi di PT.Pusaka Prima Mandiri, maka dari kasus di atas dapat disimpulkan bahwa permintaan produksi tidak sesuai dengan target produksi yang telah ditetapkan sebelumnya, maka selanjutnya bila kita bandingkan dengan yang di prolehdari data tahun 2014 yang telah diperbaiki penjadwalan produksinya, jadi dapat dilihat:

$$
\begin{aligned}
& \text { 1. } \mathrm{X}^{2} \text { hitung }=20,6385 \geq 19,6751=\mathrm{X}^{2} \text { tabel. } \text { maka } \mathrm{H}_{\mathrm{o}} \\
& \text { ditolak untuk tahun } 2013 \text {. } \\
& \text { 2. } \mathrm{X}^{2} \text { hitung }=0,05250 \leq 24,7250=\mathrm{X}^{2} \text { tabel, } \\
& \text { makaH diterima untuk tahun 2014. }
\end{aligned}
$$

Dari hasil analisis ini maka dapat diperoleh bahwa pada tahun 2014 sudah mulai membaik.walaupun masih ada keterlambatan sediki tmasih bias diatasi dengan barang produksi yang disimpan dalam gudang. Selajutnya dapat dilihat dari Tabel 10

\begin{tabular}{|c|c|c|c|c|c|c|c|}
\hline \multirow{3}{*}{\multicolumn{2}{|c|}{ No }} & \multirow{3}{*}{\multicolumn{2}{|c|}{$\begin{array}{c}\text { Produksi } \\
\text { tahun } 2013 \\
\text { Dalam ( } \\
\text { roll ) }\end{array}$}} & \multicolumn{4}{|c|}{ Produksi tahuı B.1/ B.1/2 } \\
\hline & & & & \multirow{2}{*}{\multicolumn{2}{|c|}{$\begin{array}{c}2014 \\
\text { Dalam ( roll } \\
\text { ) }\end{array}$}} & \multirow{4}{*}{$\begin{array}{c}\mathbf{2} \\
\text { jadi } \\
\text { tahu } \\
\mathbf{n} \\
\mathbf{2 0 1 3} \\
44\end{array}$} & \multirow{3}{*}{$\begin{array}{c}\text { jadi } \\
\text { tahu } \\
\text { n } \\
201 \\
4 \\
\end{array}$} \\
\hline & & & & & & & \\
\hline & & & & & & & \\
\hline 1 & Januari & 460 & 416 & 437 & 335 & & \\
\hline 2 & Februari & 378 & 370 & 408 & 407 & 8 & 1 \\
\hline 3 & Maret & 420 & 390 & 425 & 424 & 30 & 1 \\
\hline 4 & April & 227 & 198 & 440 & 440 & 29 & 0 \\
\hline 5 & Mei & 460 & 420 & 456 & 455 & 40 & 1 \\
\hline 6 & Juni & 360 & 352 & 442 & 440 & 8 & 2 \\
\hline 7 & Juli & 420 & 410 & 460 & 460 & 10 & 0 \\
\hline 8 & Agustus & 227 & 220 & 442 & 440 & 7 & 2 \\
\hline 9 & September & 375 & 370 & 452 & 450 & 5 & 2 \\
\hline 10 & Oktober & 460 & 420 & 480 & 460 & 44 & 0 \\
\hline 11 & Nopember & 420 & 416 & 442 & 440 & 4 & 2 \\
\hline 12 & Desember & 412 & 406 & 440 & 440 & 6 & 0 \\
\hline & Total & 4619 & 4388 & 5324 & 5191 & 235 & 13 \\
\hline
\end{tabular}
dibawah ini.

Tabel 10. Perbandingan Produksi 2013 dengan Produksi 2014 PT. Pusaka Prima Mandiri

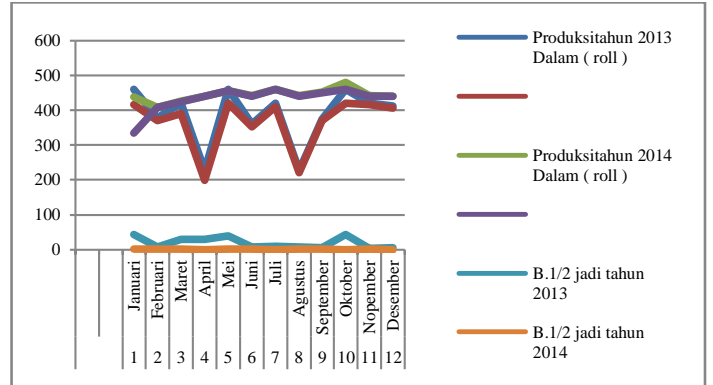

Gambar 3. Grafik Barang 1/2 Jadi Produksi tahun 2013 dan Barang $1 / 2$ jadi Produksi tahun 2014 di Pabrik PT. Pusakan Prima Mandiri.

Grafik ini menujukkan Barang 1/2 jadi Produksi tahun 2013 dan Barang 1/2 jadi Produksi tahun 2014 PT. Pusaka Prima Mandiri,dimana Barang $1 / 2$ jadi tahun 2013 berjumlah 235 roll. Sebelum Analisis perbaikan penjadwalan Produksi dilakukan pada Pabrik PT. Pusaka Prima Mandiri.Barang 1/2 jadi tahun 2014 berjumlah 13 roll.Sesudah Analisis perbaikan penjadwalan Produksi dilakukkan pada Pabrik PT. Pusaka Prima Mandiri.Maka terjadi peningkatan produksi dan pencapaian target dapat tecapai $222 / 235 \times 100 \%=0,94$ atau $94 \%$ dapat kita lihat pada Grafik diatas.94\% sebagian besar tepat waktu dan hanya $6 \%$ tidak tepat waktu.Maka dapat disimpulkan keterlambatan dapat diminimalkan

\section{KESIMPULAN}

Kesimpulan yang di proleh dari hasil pengolahan data dalam penelitian proses produksi kertas rokok di PT.Pusaka Prima Mandiri adalah:

1. PT. Pusaka Prima Mandiri belum melakukan penjadwalan secara optimal. sehingga perlu dilaksanakan perbaikan penjadwalan produksi. Agar dapat mengurangi keterlambatan produksi dengan Analisis Hasil perhitungan Makespan dengan metode CDS dan Db adalah 1889 jam di bandingkan Makespan pada Perusahaan 2.502,28 jam dengan selisih 633,28 jam atau sebesar 22,84 $\%$ Setelah dianalisa antara data 2013 dengan data 2014, maka data 2014 sudah menunjukkan penurunan barang 1/2 jadi dari 235 roll menjadi 13 roll. Sesudah. Analisis perbaikan penjadwalan produksi dilakukan. Maka terjadi peningkatan produksi dan pencapaian target dapat tercapai $222 / 235 \times 100 \%=0,94$ atau $94 \%$, ini menujukkan terjadi minimalisasi keterlambatan tinggal $=6 \%$ produksi barang $1 / 2$ jadi di pabrik PT.Pusaka Prima Mandiri.

2. Keterlambatan yang telah diidentifikasi dengan metode CDS dan Db analisis adalah delay, transportasi dan unnecessary motion menyebabkan terjadinya pemborosan waktu pada saat melakukan proses produksi.dengan perbaikan penjadwalan produksi dapat diatasi dan 
diantisivasi keterlambatannya. Sehingga dapat menghasilkan Produksi tepat waktu.

3. Pemecahan masalah (Evaluasi) yang diusulkan berdasarkan hasil yang diperoleh dengan penerapan metode CD dan Dannem bring.

a. Melakukan pengaturan penjadwalan produksi dan perencanaan kapasitas produksi yang mampu memenuhi permintaan para konsumen \& pelanggan.

b. Menghilangkan kelelahan operator dengan menyediakan fasilitas untuk istiraat seperti pemberian makan dan minum serta membagi kerja menurut jadwal shift menjadi tugas shift. Menjadi 3 shift (Lihat pada Tabel 3.3 JKK)

c. Menghilangkan kejenuhan operator dengan melakukan pertukaran elemen kerja bagi operator bagian produksi.

\section{DAFTAR PUSTAKA}

Baker,Kenneth R, 1984"Introduction ToSequen cing and Scheduling” Jonn Wiley \& Sound New York.

Barnes,Ralp M.1980,"Motion and Time Study Deasurement of work" John Wiley \& Sound New York.

Biegel,Jonh E.1978,"Production Control A Qwa ntitive Approach"Prentice Hall Of India Private Limited, New Delhi

Elsayed and Boucher, Thomas O, 1994,"Analisys and Control Production System Prestice" Hall International, Inc.

Herjato,eddy,1999."ManajemenProduksidanOperas $i$ ” PT. GramediaWidiasarana Indonesia, Jakarta.

Kusuma, Hendra,2002, "PerencanaandanPengen dalianProduksi” PenerbitAndi, Yogyakar ta.

Nasution, H. Arman,1999. "PerencanaandanPe ngendalianProduksi” PT. GunaWidya, Jakarta.

Sutalaksana.Z.Iftikar,1999,"Teknik Tata Cara Kerja” JurusanTeknikIndustri, InstitutTe knologi Bandung.

AdreseKusiato, Computation Intelligence in Design and Manufacturing, John Wihey \&Sams, United States of America. 2000.

Cross,Nigel., Engineering Design Methos, Eng land, John Wiley \& Sons, Second Editi on, 1994.

David D. Bedworth\& James F. Bailey, Integrated Production and Control Systems, Jonhn Willey \&Sams. Singapore.1987.

Baroto,

Teguh.,PerencanaandanPengendalianProdu ksi, Jakarta Ghalia Indonesia,2002.

James Riggs, Production System,"Planning Analysis and Control" Jhon Willey \&Sams, United States of America, 1976.

J.Supranto. Statistik" TeoridanAplikasi”, EdisiKe dua, PenerbitErlangga, Jakata 1991. 